\title{
Editorial
}

\section{@ccessible development: an introduction}

\author{
Koenraad Stroeken (1), Jennifer Sesabo (2), Christina Shitima (2) -
}

(I) Department of Languages and Cultures, Ghent University, Belgium

(2) Department of Economics, Mzumbe University, Tanzania

This special issue brings together a selection of peer-reviewed studies, some of which were presented in a two-day conference in August 2017 entitled @ccessible development. The conference took place in the rural setting of Mzumbe University at the foot of Tanzania's Uluguru mountains. Over the course of a week the external contributors, including a number of invited international speakers, engaged in academic exchange with a group of young Tanzanian researchers. Within the frame of a 6-year inter-university collaboration with Flemish universities on the overall topic of 'Governance and entrepreneurship through research, education and access to technology in Tanzania' a dozen or so researchers have sought to develop Mzumbe University's special focus on rural development and use of digital technology. We would like to acknowledge the role of the conference donor VLIR-UOS in its support for these academic contributions that create a synergy combining 'digitalization for development' ( $\left.\mathrm{D}_{4} \mathrm{D}\right)$, sustainable entrepreneurship, and natural resources management.

The standard format of a published collection typically involves tackling the given theme, in this case accessible development, from a comparative angle, gathering studies from different locations in Africa or across the South - and from the perspective of the same discipline. As a multidisciplinary journal, it is fitting that Afrika Focus approaches the topic of this issue from the various perspectives of several disciplines, including Pedagogy, Economics, Political Science, Information Studies, Digital Anthropology, and Development Studies. The Eastern African region features centrally in these studies. In about half of the cases the rural district of Mvomero in Morogoro Region forms the research setting. Before briefly introducing the studies, a few words are necessary on the theme that brought them together in the first place. All papers partake of a similar evolution of thought that has permeated the disciplines concerned.

\section{After paradigm: Making development accessible}

Postcolonial relations between North and South evolved from development aid to development cooperation. Implicit in this change is a shift from a one-directional dissemination to a two-way exchange of knowledge. The shift has not been easy. A rarely articulated concern understood on both sides of the fence is the question of what knowledge 
would the South have that the North might need? In practice, development agencies from the North are interested in local cultures of the South to the extent that this cultural knowledge would permit small adaptations to the model imported from the North. The goal is to facilitate and speed up implementation of evidence-based interventions, without questioning the core objectives in terms of the local perspective. The exchange between North and South is thus skewed.

Hence Arturo Escobar (1992) famously argued that a genuine integration of local knowledge and culture, a true critique of established science and technology, and a real promotion of grassroots social movements together call for the dismantling of 'development'. Local actors across the planet had actually expressed the same conviction in the first decades after Independence: as long as European states, the US or multinational companies intervene in the decision-making of the South, directly or indirectly, these societies will not be able to build confidence and find their own path. There is of course a contradiction between culture and development if the most powerful gets to define what development is and should be. This contradiction was voiced later in the classic work by Cooke and Kothari (200I). Participatory rural appraisals privilege the more highly educated, cosmopolitan members of the community, who have mastered the models and codes of the North. Setting the scene for the cherished exchange in the end always exacerbates the inequalities that arose during colonization.

A less radical reaction, pragmatic in its approach, emerged in the wake of both critiques. Uphoff (I993) argued that NGOs and collective organizations of rural development did become successful entrepreneurs by taking advantage of globalization, allowing them to escape state control and join expanding regional markets. Hickey and Mohan (2004) reacted to Cooke and Kothari by pointing out the many cases where rural participation did mean more development. The alternation between radical critique of development and its pragmatic modification has been an ongoing cycle. What made the tension difficult to resolve is the privileged position a certain group was systematically given in deciding which type of development was suitable. Research and meetings with all stakeholders, facilitated by mediators educated in the models of the North, would result in consensus about development that is 'economically viable' and 'culturally sensitive'. Once the agreed blueprint was agreed upon it could be implemented by the South. That was the illusion.

A solution to this oscillation between impractical idealism and pragmatism shorn of ideals has been to give priority to the local dynamics as they unfold in practice, without external intervention. Peet and Watts (I996) were among the first to look at political ecologies, that is: the ways in which local actors themselves take radical action. The authors prefigured the constructivist school of thought that trickled through in all domains of science. Constructivism avoids the dystopia of techno-pessimists and neo-Marxists by observing networks of actors at the heart of all technology and knowledge. Users and designers, NGO's and stakeholders, converge at nodes of the network to make value-laden choices, therefore requiring a new politics of radical democracy (Feenberg I998). 
Much has happened since the turn of the century in terms of concepts of development. In the aftermath of 9/II many events can be seen as expressions of anger, despair, and an awareness of unacknowledged frustrations and silenced voices: the activists that participate in visible networks and civil society do not cover all stakeholders (Cornwall and Coelho 2007). Many members of society do not feel represented in the networks that decide. They do not agree with the academic designation of the expert position. They may therefore turn against the progressive voices that actually try to defend their interests (Stroeken 20II). Some of the stakeholders will never encounter the researcher because they live in isolated communities or choose to remain under the radar. How might we deal with this inaccessible layer of society?

One current solution proper to the 2Ist century has been to lower the ambitions, to change the approach from interventions affecting the collective and 'society' towards offering of services and tools to individual users and their groups. This alternative is exemplified by the proactive 'enabling' state, advocated by social development theory (Midgley 20I4: 2I4). The focus on rights - a collectively guaranteed and sanctioned asset - held by individuals fits within the general approach to create the framework for a socially and culturally multi-layered dynamic improving capacity broad range of capacities. Rather than imposing a blueprint on the community, individual rights create the space for connecting uncovered behaviors and capabilities within the community. Such an approach no longer requires a privileged eye, typically a researcher or (non-)governmental expert, to mediate and translate the local wishes to the state or donor, and vice versa: to translate expectations from the North. Such an approach dares to rely on people's communicative capacities and networks. At a macro-level, the new approach is in line with the Accra Agenda for Action concluded in 2008 wherein more than 80 developing countries and over 3000 civil society organizations agreed to end the fragmentation of aid in projects, but also to stimulate ownership among recipients and allow for the choosing of local providers, thus freeing aid from the donor country (Holvoet 20I0).

The present collection of papers inscribes itself in the new approach striving for what we coined 'accessible' development. Several components constitute the access variable, which in our definition goes beyond simply the availability of a service, to include, rights of use, actual use, an enabling environment, and decision-making power or autonomy of use (permitting self-steering implementation). The guiding metaphor of accessible development is the smartphone, popular in Africa as in the rest of the world. The device connects the user to multiple platforms, allowing for goal-oriented exchange, such as buying and selling, thus skipping the middle men and cutting across cultural and social barriers. The user of the smartphone seemingly has access without depending much on gate-keepers. With the help of the right app, an individual can decide on opportunities of doing business in rural settings, of setting up a community initiative, of commenting on a service or monitoring the use of a natural resource. Trust in the user's autonomy and optimism about outcomes that benefit the collective go against the grain of earlier development studies. 
At the same time, the concept of @ccessible development raises questions: is access to technology direct or indirect, potential or actual, coincidental or structured, equitable or not equitable, and so on? If technology, such as an e-learning tool, is made freely available, the main question becomes how accessible it actually is for the user. Access is determined by both constraints and incentives. Which 'impediments' to use persist, such as language, education, social and cultural background? What interventions are possible that will increase awareness of the tool's existence? Included in the barriers and the stimuli of usage are the series of previous selections made by donors and designers of the technology or service. These research questions, rooted in the field of e-learning, can be extrapolated to the domains of governance and entrepreneurship, because all disciplines have had to deal with the postcolonial debate on the relation between North and South. Making development accessible requires social innovation, exploring new ways of connecting members of the community to knowledge and technology.

\section{Enabling environments: overview of the collection}

There are different ways to arrange papers in a volume such as this, but in line with the conference out of which the present work has emerged, this issue arranges the papers around the theme of accessible development. Each study can be claimed to highlight an aspect of the matter at hand: how to make the available tool or service of development more accessible? The first category of studies concentrates on the barriers to uptake. The second category explores the incentives, in particular ways of creating an enabling environment. In the first category, Ghasia, Desmet, Machumu, and Musabila identify financial, pedagogical, technological, infrastructural, individual- and policy-related challenges that obstruct the successful deployment of mobile learning in four Higher Learning Institutions (HLIs) in Tanzania. The barriers include limited network coverage, students' lack of resources to purchase mobiles, lack of qualified staff in mobile content preparation and administration, gaps in the existing policies, and faulty course design. For users to access the development tool of mobile-learning (m-learning), active support should be given first to the providers of the tool's content. Institutions allotting funds and time should sometimes dare to defy the 'client is king' truism. Mark Kaahwa has established that around half of the teachers and students of a Ugandan university regard themselves as having insufficient ICT-skills. Such incapacity is all the more problematic since advanced ICT skills correspond to better performance on the three variables that make for an effective e-learning experience. Almasi, Zhu, and Machumu identify the three variables as: teaching, social and cognitive presence, and, respectively, the teacher's virtual prediction of the learning process, the sense of interacting with other participants, and the actual attention of the user. Within the higher learning population the skills gap may widen in an educational environment that promotes self-study involving less teacher contact, less physical interaction with other learners, and less, immediate face-to-face feedback. In terms of the second category of social and cognitive presence, Machumu, Zhu and Almasi, in their study of Ioro undergraduate students participating in a constructivist blended-learning environment, conclude that motivational factors (e.g. 
extrinsic goal and intrinsic goal, task valuation, and self-efficacy) were positively correlated with student engagement learning strategies. Development tools become accessible only as users are motivated. Intrinsic and extrinsic rewards, through which the tool motivates the user, should therefore be considered. Focussing in on ways to improve access, Bram Pynoo working with teacher trainers shows how collaborative design teams can contribute to integrating ICT in learning. Although team leadership plays a role, the intensity of networking and the personal interest of the members are also important, especially during sessions of limited duration. The results are in line with the constructivist model, which lets the impact of technology depend on an enabling environment. To better ascertain what such environment should be like, Wouter Grove, in his action-study of two emerging African digital platforms, UDUBSit and Mfunzi, looks into the ecosystem of collaborative design teams. How do locally relevant, socially embedded digital platforms facilitate continuous innovation? He investigates the potential of the Living Labs methodology for facilitating the seemingly paradoxical concept of "designed serendipity".

From the problem of users accessing ICT we move to the field of governance. Few people today will doubt the importance of clean energy sources, including renewable energy, but as Lyakurwa and Mkuna argue, government agencies seem unable to coordinate energy access and unable to address efficiency issues, while ward and village leaders are often not in agreement. Therefore, rural Tanzanians hesitate to shift from using local wood or charcoal, which destroy their environment, to electricity. The study recommends that universities help to inform and educate the community about the costs and benefits of using clean energy sources.

The paper by Ngowi, Genda and Salema reveals that the majority of youth living along the ecologically vulnerable Great Ruaha River in Iringa do not participate in the Water Committee activities. Water governance at the local level can only improve by increasing accessibility for all, in particular by integrating youth participation, for example allowing the youth to patrol sources and fetch water at night. Additional technological interventions such as the establishment of water pumping stations at a distance from the dam can reduce environmental degradation.

Christina Shitima in her application of intersectionality theory finds that culture affects people's access to river basin resources along the Kilombero River. The norms that deny women rights to use these resources are reflected in a gendered distribution of labor and related income-generating activities. Women score low on both the rights of use and benefits of using a resource. Yet, more heterogeneity appears when the context is looked at more closely. Within a fishing community, age most strongly determines use, which may indicate division of labor. By identifying barriers to access the researchers are able to suggest feasible interventions for improvements, such as anti-sexist and anti-ageist campaigns.

Examining the beekeeping sector in Tanzania, Nicholaus Tutuba acknowledges some of the known factors hindering commercialization: overreliance on traditional hives and methods of honey production, low volumes, production of poor quality honey, constrained access to finances and reduced fodders. However, through a method of men- 
tal mapping points, his analysis identifies beekeeping expertise and management as the two critical variables underlying the aforementioned series of factors. Jasinta Msamula, in a qualitative study together with Tutuba on value creation activities of micro and small enterprises (MSEs) in rural Tanzania, describes the influence of institutions on the utilization of natural resources, particularly in the wood furniture manufacturing industry. Factors that play a role in commercial success and survival are the compliance of rural MSEs to regulations, the level of enforcement of regulations by the government, MSEs knowledge of regulations, and regulatory costs. Policy-makers are advised to intervene in those domains to raise accessibility.

Finally, applying a logistic regression model, Nsubili Isaga describes the trouble Tanzanian smallholder farmers have in securing bank credit for their investments. Obstacles to access are the value of collateral, the lack of information about how banks issue loans, and the geographic distance to the banks. The study recommends for the establishment of a national bank of agriculture, which will cater for the specific situation of farmers and put trust in cooperative unions, while accelerating the needed shift from subsistence to commercial farming. To overcome the collateral barrier the author advises African governments to more smoothly issue certificates of occupancy to their citizens.

\section{Future directions}

Taken together the studies outlined above highlight the salience of rights and the relevance of the user's experience in developmental research. At the same time, they indicate that individual rights are no guarantee of access. Knowledge, motivational and normative sensitizing should be actively stimulated. Still, rights can retain an individualist bias, but such a bias can be mitigated by an enabling environment, which might include group and community-building, whether in the frame of designer teams, local committees, managed micro-enterprises, or existing rural communities.

To be called accessible, offering the rights to use cannot suffice as intervention. Equality of opportunity is not enough. Access i.e. benefiting from one's right, means physically accessing the service or resource. Therefore, the barriers have to be taken down and the incentives activated. An old debate, however, resurfaced during the conference discussions. If opportunities are equally distributed, should the actual outcomes not be compared according to the groups of stakeholders, thus possibly calling for corrective interventions, which would entail the redistribution of resources? The simultaneous application of two opposing economic principles within the concept of accessible development did not seem logical. The analogy was made with a parent giving two children an equal amount, yet at a later stage compensating the one failing to invest in order to ensure that the outcome remained equal for both. The question is ongoing: how to make access sustainable, meeting people's needs without frustrating some and thus compromising future use? From future research we expect and look forward to more insight from mixed methods that complement statistical data with qualitative research, fieldwork, and longitudinal data. 


\section{References}

Cooke, B., \& Kothari, U. (Eds.). (200I). Participation: The new tyranny? Zed books.

Cornwall, A., \& Coelho, V. S. (Eds.). (2007). Spaces for change? The politics of citizen participation in new democratic arenas (Vol. 4). Zed Books.

Escobar, A. (1992). Reflections on 'development': grassroots approaches and alternative politics in the Third World. Futures, 24(5), 4II-436.

Feenberg, A. (1998). Questioning technology. Routledge.

Hickey, S., \& Mohan, G. (2004). Participation from tyranny to transformation? Exploring new approaches to participation in development. Zed books.

Holvoet, N. (2010). Gender Equality and New Aid Modalities: Is Love Really in the Air? The European Journal of Development Research, 22(I): 97-II7.

Midgley, J. (2014). Social development: Theory and practice. Sage.

Peet, R., \& Watts, M. (1996). Liberation ecologies: environment, development and social movements. Routledge.

Stroeken, K. (Ed.). (20II). War, technology, anthropology. New York: Berghahn Books.

Uphoff, N. (1993). Grassroots organizations and NGOs in rural development: Opportunities with diminishing states and expanding markets. World Development, 2I(4), 607-622. 